\title{
Proposta de matriz para a análise da publicidade na web
}

\section{Taís Steffenello Ghisleni}

Doutora; Universidade Federal de Santa Maria, Santa Maria, RS, Brasil taisghisleni@yahoo.com.br

\section{Eugenia Maria Mariano da Rocha Barrichello}

Doutora; Universidade Federal de Santa Maria, Santa Maria, RS, Brasil eugeniabarichello@gmail.com

\section{Resumo}

Este artigo apresenta uma matriz metodológica para análise de anúncios publicitários em websites, e a sua construção está embasada nas teses de Marshall McLuhan e Neil Postman, sob a vertente ecológica, e também nas propostas de Pinho, Sebastião, McMillan, Fernandes e Duarte. A matriz foi construída utilizando a cartografia como estratégia metodológica, pois permite acompanhar os movimentos de transformação da paisagem e seus resultados evidenciam que as possibilidades oferecidas pela tecnologia são responsáveis por mudanças nas práticas publicitárias, considerando-se que a cada novo aspecto inserido, novas experiências foram proporcionadas e a publicidade foi construindo o seu espaço na web.

\section{Palavras-chave}

Estratégias comunicacionais. Publicidade na web. Ecologia midiática. Cartografia na Comunicação. Anúncios publicitários.

\section{Introdução}

Este estudo faz parte de uma pesquisa mais ampla, inserida na linha de Pesquisa "Mídia e Estratégias Comunicacionais", na área de concentração "Comunicação Midiática", do Programa de Pós-graduação em Comunicação da Universidade Federal de Santa Maria e teoricamente ancora-se na escola de pensamento denominada Ecologia da Mídia, que tem se destacado pela ênfase dada ao estudo do impacto cultural das tecnologias e dos meios de comunicação nas sociedades, ao longo dos anos. 
A noção de ecologia da mídia parte de uma perspectiva da mídia como ecossistema e observa as relações entre os seres vivos e o meio ambiente onde vivem, bem como a influência que cada um exerce sobre o outro tendo como suporte as tecnologias digitais. As “[...] novas tecnologias midiáticas permitiram que o mesmo conteúdo fluísse por vários canais diferentes e assumisse formas distintas." (JENKINS, 2009, p. 36). Sendo que a convergência acontece através da relação dos consumidores com o meio e de suas interações sociais. Destacamos que a busca por novas formas de divulgação de mensagens publicitárias que acontece na atual ecologia midiática obriga as organizações a buscar novas tecnologias ou ainda, novas formas de utilizá-las. Os estrategistas de comunicação precisam considerar que as tecnologias agora funcionam como ferramentas e que estão aí para serem exploradas, e que a cada dia surgem novas opções para serem utilizadas.

A ecologia midiática funciona, portanto, como um conceito importante para se compreender a dinâmica intermidiática na contemporaneidade, assim como os processos interacionais que a atravessam. Juntamente com as mudanças que impulsionam a busca por novas tecnologias e por novas formas de utilizá-las, surge a necessidade de pensarmos em maneiras de analisar e compreender essas interações.

Diante destes pressupostos, o presente artigo tem como objetivo apresentar uma matriz metodológica de análise da publicidade na ambiência digital (GHISLENI, 2016), especificamente voltada para a análise de anúncios em websites.

0 trabalho está estruturado da seguinte forma: primeiro, serão discutidos conceitos relacionados à ambiência digital, tais como cenários da Web, interação e interatividade e tecnologias; em segundo, será abordada a publicidade digital, com seus tipos e tarefas, formatos e interatividade em anúncios; e em terceiro, será apresentada a matriz elaborada para a análise dos anúncios em websites. Para tanto, o trabalho está embasado nas teses de Marshall McLuhan e Neil Postman, que fundamentam a vertente ecológica, mas também nas propostas de Pinho (2001), Sebastião (2011), McMillan (2002), Fernandes (2011), Duarte (2011).

\section{Ecologia midiática e a ambiência digital}

A metáfora ecológica começou a ser utilizada no contexto da comunicação na década de 1960 por Neil Postman e Marshall McLuhan. Foi por “[...] intermédio de McLuhan que o 
campo da ecologia da mídia emergiu e adquiriu existência reconhecível, de maneira que, em certo sentido, McLuhan foi a causa formal da ecologia midiática." (STRATE, 2011, p. 5).

Strate (2011) explica que a ecologia midiática é uma abordagem que ajuda a entender como nos adaptamos aos ambientes e como estes atuam sobre nós, seja de forma positiva ou negativa, mas certamente afetando-nos. Isto posto, é possível compreender a publicidade inserida no ecossistema midiático, pois, embora seu objetivo principal ainda seja o de persuadir, as suas práticas foram se modificando ao longo dos anos, especialmente a partir das tecnologias a que somos expostos. A publicidade digital ganhou força, pois consegue mostrar o retorno que traz para as empresas, é objetiva e espalha seus banners em todo o ecossistema da internet oferecendo, além dos produtos, emoções, criação de vínculos e dando início a novos relacionamentos.

O que mudou na forma de fazer publicidade, desde os primórdios da profissão até os dias atuais é que a interrupção por si só já não conquista a atenção dos consumidores e, por este motivo, a publicidade precisa ser, cada vez mais, parte de um contexto, precisa trazer conteúdo, precisa interagir com seus públicos.

A ecologia dos meios é construída com base em uma série de considerações teóricas que reforçam que o ambiente criado pelas tecnologias de comunicação afeta quem os utiliza (SCOLARI, 2010), ou seja, a forma com que os usuários consomem os anúncios publicitários também modifica como os próximos anúncios vão ser construídos e onde serão expostos.

Scolari (2012) ressalta que é chegada a hora de ir além da mera descrição e começar a desenvolver ferramentas teóricas e metodológicas para o estudo aprofundado da ecologia de mídia. 0 autor informa ainda que a diferença entre antigos e novos meios de comunicação não é um fato teoricamente importante já que "novos" meios de comunicação de hoje, serão os "velhos" de amanhã.

Meyrowitz (1984) aborda a relação entre mídia e ambiente ${ }^{1}$ e considera que "A natureza da interação não é determinada pelo ambiente físico enquanto tal, mas pelos modelos de fluxos informativos." (MEYROWITZ, 1984, p. 60). Reforçamos que a interação é ampla e coloca em cena os atores, possibilitando as trocas de influências entre pessoas, seja por meio de conversas ou gestos, mas que ela também inclui o conceito de interatividade, ou seja, a mediação realizada com um meio tecnológico, como por exemplo, um computador.

\footnotetext{
${ }^{1}$ Meyrowitz tem uma concepção diferenciada de Goffman que considerava que os comportamentos aconteceriam somente no interior de espaços físicos perceptíveis.
} 
Strutzel (2015, p. 129) explica que:

Por volta do ano 2000, usava-se muito esse termo [interatividade] para definir a nova geração e sites que possuíam recursos de Java ${ }^{2}$ e Flash ${ }^{3}$. Mas a amplitude do conceito de interatividade só veio com a utilização do conceito de redes sociais e dos aplicativos mobile, em que os usuários de fato interagem e desfrutam de experiências ricas com a plataforma e com outros usuários.

Diante do contexto, a situação social pode ser alterada pela introdução de novos meios de comunicação. "As mudanças na maneira como nos comunicamos podem mudar a própria natureza de um sistema social, de forma que, por exemplo, quanto mais elevada a quantidade de atos de comunicação, maior a sociedade." (STRATE, 2011, p. 8).

O foco central do estudo da ecologia das mídias está na pergunta: "O que as mídias (as tecnologias) têm feito por nós, ou para nós?"4 (MEYROWITZ, 2008). Para encontrar a resposta desta pergunta é preciso observar o contexto de todos os ângulos possíveis, sem se fechar para qualquer vertente. "Para entendermos a futura estrutura dos sistemas sociais, precisamos contemplar a atual estrutura dos sistemas de comunicação, a atual estrutura do ambiente das novas mídias." (STRATE, 2011, p. 20).

O ecossistema midiático torna-se mais complexo a partir da popularização das tecnologias e "[...] a emergência de novos espaços de interação, especialmente nos suportes digitais, amplia as possibilidades de resposta e interpretação dos interagentes" (BARICHELLO, 2014, p. 42) que agora têm seus próprios espaços de atuação e o poder de trazer à tona questões que consideram pertinentes.

A internet comercial começou no Brasil com poucos usuários (REDAÇÃo ADNEWS, 2016) e, hoje, já são mais de 112 milhões de brasileiros, e continua crescendo. De lá para cá, muita coisa mudou e testemunhamos mudanças significativas neste processo. Mudanças essas alavancadas pelas tecnologias digitais e pelas transformações da Web e do consumidor, que foram classificadas pela O’Reilly Media em três ondas conhecidas como

\footnotetext{
2 JavaScript é uma linguagem de programação que é executada dentro do navegador (browser) e possibilita criar efeitos, como por exemplo, fazer uma imagem aumentar de tamanho quando passamos o mouse em cima. O JavaScript também consegue detectar a resolução da tela (notebook, netbook, tablet, smartphone) e exibir o conteúdo de um site de uma maneira mais adequada para cada tipo de dispositivo.

3 Surgindo na década de 1990, o Flash era um software da extinta Macromedia voltado para a criação de animações vetoriais. Os arquivos gerados em formato .swf (Shockwave Flash File) reuniam gráficos, vídeos, sons e scripts, executados nos navegadores através de um plug-in original de fábrica ou instalado pelo usuário. Browsers sem esse acessório não rodavam as animações, o que costumava "matar" muitos sites. No início dos anos 2000 o Flash virou uma verdadeira febre na Internet. Presença obrigatória nos sites mais descolados, muitas vezes o recurso exigia uma banda de navegação que poucos mortais dispunham para acessar a rede. Em 2005, a Adobe Systems comprou a Macromedia e passou a chamar o aplicativo de Adobe Flash (VEGAWEB, 2016).

4 What do media do to us or for us?
} 
Web 1.0, Web 2.0 e Web 3.0 (GABRIEL, 2010). A autora explica que os termos utilizados não sugerem novas versões para a web, eles constituem-se em uma divisão didática, sem qualquer atualização das suas especificações técnicas. As mudanças se relacionam mais com o comportamento dos usuários web do que com as tecnologias que proporcionaram essas mudanças. 0 quadro 1 sintetiza as características de cada onda.

Quadro 1 - Características da Web 1.0, 2.0 e 3.0

\begin{tabular}{|c|c|}
\hline $\begin{array}{c}\text { Divisão } \\
\text { didática }\end{array}$ & Características \\
\hline Web 1.0 & $\begin{array}{l}\checkmark \text { É a web estática, onde as pessoas apenas navegam e consomem informações. } \\
\checkmark \text { A informação era difundida e não havia uma resposta do usuário àquele } \\
\text { conteúdo, seja por falta de tecnologia, seja pelo foco das empresas, portais de } \\
\text { notícias, etc. }\end{array}$ \\
\hline Web 2.0 & $\begin{array}{l}\checkmark \text { A Web } 2.0 \text { não se limita mais à plataforma PC. } \\
\checkmark \text { É a web da participação, onde as pessoas usam a web como plataforma para } \\
\text { todo tipo de interação: blogs, vídeos, fotos, redes sociais. } \\
\checkmark \text { É a web como plataforma de participação, por meio da qual não apenas se } \\
\text { consomem conteúdos, mas principalmente na qual se colocam conteúdos. Blogs, } \\
\text { sites de publicação de vídeo (como o YouTube) e redes sociais (como Orkut, } \\
\text { MySpace, Facebook etc.) são exemplos das suas ferramentas participativas. } \\
\checkmark \text { É o que chamamos de computação em nuvem - os aplicativos (como Gmail, } \\
\text { redes sociais etc.) ficam na internet (nuvem de computadores) acessados por } \\
\text { meio de computadores com conexão online. Hoje, a predominância de } \\
\text { informações na web é documentada. [...]. Nesse cenário emergente, para } \\
\text { conseguirmos atuar na web e encontrar o que é relevante a cada instante, } \\
\text { precisaremos de um novo paradigma de busca e organização da informação e } \\
\text { esse novo paradigma é a Web 3.0, ou a web semântica. }\end{array}$ \\
\hline Web 3.0 & $\begin{array}{l}\checkmark \text { Na web semântica, além da informação em si, o contexto e as ligações referentes } \\
\text { a essa informação permitirão encontrar um significado que auxilie o uso da web. } \\
\checkmark \text { A Web } 3.0 \text { é definida pelo aperfeiçoamento contínuo da tecnologia e pelos } \\
\text { aplicativos da web, e possivelmente, a inteligência artificial. } \\
\checkmark \text { A Web } 3.0 \text { representa uma época de convergência contínua de aparelhos de } \\
\text { recepção, associando a mídia tradicional e a social, com o aumento da rede sem } \\
\text { fio, e a web semântica modificará o cenário do marketing. } \\
\checkmark \text { É uma extensão da web atual, na qual as informações fornecem um sentido bem- } \\
\text { definido, por meio de tags como HTML. }\end{array}$ \\
\hline
\end{tabular}

Fonte: Adaptado de Gabriel (2010, p. 79-80) e Strauss e Frost (2011, p. 20).

É importante entender que a interação e as possibilidades oferecidas pela tecnologia são responsáveis por várias mudanças que as práticas publicitárias sofreram desde que ingressaram na ambiência digital. A cada novo aspecto inserido, novas experiências foram proporcionadas e mais elementos puderam ser observados. Se na web 1.0 as informações eram unidirecionais, na web 2.0 as informações passaram a ser partilhadas entre os usuários até chegar à web 3.0, que já possibilita uma comunicação mais colaborativa e intuitiva. 
Entendemos as práticas publicitárias enquanto “[...] ações produtivas da classe profissional, [ou seja, tudo que cerca a produção publicitária] que organizam um trabalho sistemático e consciente de produção de imagens de propaganda e de discussão do lugar destas imagens no meio social." (GENARO, 2012, p. 257). Segundo Genaro (2012), estas articulações sociais são responsáveis pela criação das novas visualidades que disciplinam as formas sociais de interação e acontecem de forma ampla, por toda a classe profissional.

O Quadro 2 expõe algumas tarefas que a publicidade utiliza para exercitar as suas práticas, na visão de Pinho (2001).

Quadro 2 - Práticas de publicidade

\begin{tabular}{|c|l|}
\hline PRÁTICA/TAREFA & \multicolumn{1}{|c|}{ EFEITO/OBJETIVO } \\
\hline $\begin{array}{c}\text { Divulgação da marca (de } \\
\text { produto/serviço) ou } \\
\text { empresa }\end{array}$ & $\begin{array}{l}\text { Para torná-la mais íntima dos consumidores que já a conhecem } \\
\text { e/ou fazê-la conhecida pelos que não a conhecem. }\end{array}$ \\
\hline $\begin{array}{c}\text { Promoção da marca ou } \\
\text { empresa para seus } \\
\text { consumidores }\end{array}$ & $\begin{array}{l}\text { Visando a aumentar sua presença entre eles ou ressaltando seus } \\
\text { aspectos mais competitivos em relação ao que existe no mercado } \\
\text { e é oferecido pela concorrência. }\end{array}$ \\
\hline $\begin{array}{c}\text { Criação de mercado para a } \\
\text { marca ou empresa }\end{array}$ & Através da conquista de consumidores. \\
\hline Expansão do mercado & Através da conquista de mais consumidores. \\
\hline $\begin{array}{c}\text { Correção do mercado } \\
\text { Educação do mercado } \\
\text { estes não estiverem corretamente informados das características } \\
\text { e vantagens do produto ou serviço do anunciante. }\end{array}$ & $\begin{array}{l}\text { Quando o consumo depender da formação de uma atitude ou } \\
\text { hábito do consumidor. }\end{array}$ \\
\hline Consolidação do mercado & $\begin{array}{l}\text { Quando o importante for solicitar uma posição conquistada, } \\
\text { através de reafirmação das qualidades da marca ou empresa. }\end{array}$ \\
\hline Manutenção do mercado & $\begin{array}{l}\text { Através da constante reafirmação das características e vantagens } \\
\text { da marca ou empresa e da ação de resposta aos ataques e } \\
\text { esforços da concorrência. }\end{array}$ \\
\hline
\end{tabular}

Fonte: Adaptado de Pinho (2001, p. 174-175),

Entendemos que as práticas publicitárias são institucionalizadas dentro de um processo no qual os profissionais tomam para si o controle do campo, e da produção de anúncios, de forma geral. Esta construção implica em “[...] falar na organização de agentes que ao mesmo tempo produzem, pensam e discutem a inserção das imagens no meio social." (GENARO, 2012, p. 260).

A publicidade pode ser caracterizada em dois tipos: publicidade com objetivos promocionais e publicidade institucional. A primeira "[...] é a ação de divulgar produtos e serviços apresentando seus atributos e benefícios com o intuito de torná-los conhecidos 
para os consumidores." (GONÇALES, 2009, p. 17). Explora os aspectos positivos e influencia com base na persuasão. Já a segunda trabalha para valorizar marcas e empresas. "Busca apresentar a filosofia, metas, objetivos e ações das organizações, tentando obter uma simpatia e construir uma boa imagem para os consumidores." (GONÇALES, 2009, p. 17). Esta publicidade tende a valorizar a marca no mercado, afirmando suas qualidades. 0 autor reforça que independente da classificação utilizada a informação tende a persuadir o público-alvo, que seus atos são parciais e intencionais e procuram sempre induzir, mesmo que a longo prazo, uma ação de compra.

Dentro da publicidade com objetivos promocionais, Pinho (2001) nos apresenta uma nova divisão.

Quadro 3 - Tipos de publicidade comercial/promocional

\begin{tabular}{|c|c|}
\hline TIPO DE PUBLICIDADE & EFEITO/OBJETIVO \\
\hline Publicidade de produto & $\begin{array}{l}\text { Tem por objetivo divulgar um produto, levando o consumidor ao } \\
\text { conhecimento e à compra. }\end{array}$ \\
\hline Publicidade de serviços & $\begin{array}{l}\text { Procura "vender" serviços - de bancos, financeiras, seguradoras, } \\
\text { agências de turismo, entre muitos outros. }\end{array}$ \\
\hline $\begin{array}{l}\text { Publicidade genérica (ou } \\
\text { de commodities) }\end{array}$ & $\begin{array}{l}\text { É a publicidade pioneira, que injeta informação em um dado sistema } \\
\text { de marketing; realiza a coordenação dos programas de informação } \\
\text { entre produtos com objetivos comuns; e, destaca os atributos } \\
\text { comuns de uma designação mais apropriada no caso da promoção de } \\
\text { produtos agropecuários que pertencem a um determinado grupo de } \\
\text { commodities. }\end{array}$ \\
\hline Publicidade de varejo & $\begin{array}{l}\text { Os produtos anunciados são patrocinados pelo intermediário, no } \\
\text { caso, o varejista. }\end{array}$ \\
\hline $\begin{array}{l}\text { Publicidade de } \\
\text { classificados }\end{array}$ & $\begin{array}{l}\text { Os anúncios classificados divulgam mensagens de compra, venda ou } \\
\text { aluguel de imóveis, móveis, serviços profissionais, empregos. }\end{array}$ \\
\hline Publicidade comparativa & Faz alusão aos produtos e serviços dos concorrentes. \\
\hline Publicidade cooperativa & $\begin{array}{l}\text { Anuncia a venda de um produto conjuntamente pelo fabricante com } \\
\text { o lojista. Os anúncios são realizados em conjunto. }\end{array}$ \\
\hline Publicidade de promoção & $\begin{array}{l}\text { Divulga a promoção de vendas por meio de anúncios e comerciais } \\
\text { veiculados nas mídias. }\end{array}$ \\
\hline Publicidade legal & $\begin{array}{l}\text { Compreende anúncios cuja publicação é exigida das empresas de } \\
\text { capital aberto, de fundações, de cooperativas, de associações e } \\
\text { entidades de classe, dos órgãos da administração pública direta ou } \\
\text { indireta, por lei ou regulamentação específica. }\end{array}$ \\
\hline
\end{tabular}

Fonte: Adaptado de Pinho (2001, p. 176-177).

De forma geral, as práticas permanecem ao longo do texto, o que modifica é o contexto que as cerca. No cenário em questão, o que mudou realmente foi a importância desempenhada pelo conhecimento e pela informação, já que as mudanças da sociedade 
estão vinculadas às novas tecnologias que impactam, não apenas a produção de bens e serviços, mas todo o conjunto das relações sociais.

Considerando-se os efeitos da internet, segue-se a perspectiva de McLuhan ${ }^{5}$ (2007) que considera que o ambiente se transforma intermitentemente sob a influência das novas tecnologias. Os meios de comunicação não desaparecem, mas as formas de acesso ao seu conteúdo é que são substituídas por novas ferramentas tecnologicamente mais avançadas. E a publicidade assimilou este fato, pois não oferece mais apenas o produto, e sim, sensações e emoções ao consumidor. Atualmente, as marcas querem mais do que apenas vender, elas querem criar vínculos de confiança e estabelecer relacionamentos em longo prazo. Strutzel reforça que "[...] neste novo modelo, a qualidade e a intensidade do relacionamento entre a marca e o consumidor é o principal fator de sucesso." (STRUTZEL, 2015, p. 9).

Só que para atingir o consumidor, a publicidade precisa estar aberta para mudanças nas suas práticas, tornando-a mais profunda, assertiva e consciente que as pessoas e as marcas estão constantemente mudando, buscando novas experiências e sensações. 0 desafio da publicidade, hoje, é entender o que de fato as pessoas querem e agir no sentido de satisfazer essas necessidades, estimulando o uso de práticas cada vez mais tecnológicas para entender o indivíduo e fornecer aos mesmos, experiências memoráveis. Com isso, as estratégias tornaram-se mais complexas, e entendendo que ambiência online passou a ser o principal canal de relacionamento, a vantagem competitiva se dá na presença digital eficiente (STRUTZEL, 2015).

\section{Publicidade na web}

Entre os principais papéis desempenhados pela publicidade está a função de “[...] transmitir mensagens cuja intenção é persuadir os consumidores a comprar determinados produtos ou serviços." (ADLER; FIRESTONE, 2002, p. 20) e garantir a viabilidade comercial dos veículos de comunicação. Especialmente com o advento das novas tecnologias que intensificou as relações entre produtores e consumidores, mas ao mesmo tempo ampliou as possibilidades de interesse do público alvo, fazendo com que a atenção, antes destinada ao conteúdo dos anúncios, agora seja muito mais disputada. Os autores reforçam que "O primeiro desafio de todo o anunciante é chamar e manter a atenção do público-alvo, e num

${ }^{5}$ A obra original foi traduzida para o português na década de 1960. 
mundo onde a atenção é um bem escasso, isso não é tão simples de se obter." (ADLER; FIRESTONE, 2002, p. 20).

A publicidade na Internet pode ser considerada menos intrusiva, já que a mesma oferece ferramentas para controle da exposição dos seus anúncios. Manifestou-se inicialmente nos sites empresariais que ofereciam informações sobre seus produtos e serviços (PINHO, 2000) e hoje, o setor de publicidade, segundo pesquisa IBGE (apud FOLHA DE S. PAULO, 2013, doc. eletrônico $)^{6}$, “[...] movimenta uma indústria de R\$ 116 bilhões (3,15\% do PIB). 0 número corresponde ao faturamento de setores e empresas que vivem de publicidade e patrocínios.". Essa grande movimentação financeira proporciona um momento de transformação no qual a essência do trabalho ainda permanece a mesma, mas as ferramentas utilizadas estão se alterando.

Com a era digital, empresas e agências de comunicação e publicidade estão diante de novos desafios. E a publicidade na Internet possibilita divulgação massiva, para mercados nacionais e internacionais, e ao mesmo tempo, consegue focar segmentos específicos de mercado (PINHO, 2000). "Os primeiros modelos de publicidade na Web foram os banners e botões ${ }^{7}$ que se assemelhavam ao formato impresso tradicional, já que apareciam dentro de contornos claramente definidos." (ZEFF; ARONSON, 2000, p. 25). Entretanto, o contexto foi se alterando de acordo com as possibilidades tecnológicas e outros tipos, as vezes mais e as vezes menos intrusos foram se inserindo ao ecossistema. 0 que deve ser considerado é que com as capacidades que a Web oferece, de misturar áudio, vídeo e interatividade, abre-se um leque de oportunidades para o exercício da criatividade ser expresso através dos anúncios publicitários.

Quanto aos formatos, é possível perceber que os anúncios na internet já evoluíram muito, especialmente com o surgimento da publicidade digital; o incremento do uso de banda larga; e o aumento dos investimentos dos anunciantes na internet. Essas inovações abriram mais espaço para a criatividade e com isso, os anúncios tornaram-se mais atraentes. 0 uso da banda larga ampliou a visibilidade dos banners e a aposta dos anunciantes na publicidade digital encoraja os veículos a oferecerem cada vez mais formatos novos, diferenciados e Sebastião (2011) sistematizou 3 principais formatos de anúncios publicitários digitais utilizando como base o critério de apresentação ao utilizador, são eles: os anúncios de pesquisa; os anúncios de exibição (display ads); e os classificados.

\footnotetext{
${ }^{6} \mathrm{O}$ estudo foi encomendado pela Associação Brasileira das Agências de Publicidade (ABAP) para o IBGE em 2013.

7 “É a denominação genérica de um anúncio banner de pequenas dimensões (88x31pixéis) que pode ser colocado em qualquer parte de uma página da Web, sendo lincado ao site do seu patrocinador." (ZEFF; ARONSON, 2000, p. 50).
} 
Quadro 4 - Principais formatos de anúncios publicitários conforme apresentados ao utilizador

\begin{tabular}{|c|c|c|}
\hline Formato & Tipo & Descrição \\
\hline \multirow{3}{*}{$\begin{array}{l}\text { ANÚNCIOS DE } \\
\text { PESQUISA }\end{array}$} & Listagem & $\begin{array}{l}\text { Relacionada com o posicionamento do anúncio numa } \\
\text { determinada pesquisa feita por palavra-chave. Este } \\
\text { posicionamento depende do valor pago pelo anunciante e das } \\
\text { palavras-chaves pesquisadas. }\end{array}$ \\
\hline & Contextuais & $\begin{array}{l}\text { Associados ao conteúdo do website e não ao tipo de pesquisa } \\
\text { efetuada pelo utilizador. }\end{array}$ \\
\hline & $\begin{array}{l}\text { Inclusão } \\
\text { paga }\end{array}$ & $\begin{array}{l}\text { Garante a ligação ao motor de busca independentemente do tipo } \\
\text { de pesquisa feito pelo utilizador. }\end{array}$ \\
\hline \multirow{3}{*}{$\begin{array}{l}\text { ANÚNCIOS DE } \\
\text { EXIBIÇÃO }\end{array}$} & Banner & $\begin{array}{l}\text { Espaço horizontal de uma página web que a anunciante paga. } \\
\text { Neste espaço é apresentado determinado conteúdo estático ou } \\
\text { hipertextual. Subtipos: } \\
\text { - Leaderboard - banner horizontal } 728 \times 90 \text { pixeis, normalmente } \\
\text { situado no topo ou no fundo do suporte; } \\
\text { - MREC - banner } 300 \times 250 \text { pixeis normalmente situado no topo } \\
\text { ou no fundo do suporte; } \\
\text { - MREC Vídeo - formato com as mesmas características do MREC } \\
\text { e que suporta vídeo. }\end{array}$ \\
\hline & $\begin{array}{l}\text { Pop-up } \\
\text { pop-under }\end{array}$ & $\begin{array}{l}\text { Janela intrusiva que surge no ecrã quando o utilizador navega em } \\
\text { determinada página. O pop-up surge sobre o conteúdo impedindo } \\
\text { a leitura do mesmo; o pop-under surge por trás desse conteúdo } \\
\text { invadindo o espaço do ecrã, mas não impede a sua visualização. } 0 \\
\text { utilizador tem a opção de os fechar. Subtipo: } \\
\text { - Intersticial - pop-up com o tamanho da página que oculta } \\
\text { totalmente o seu conteúdo. }\end{array}$ \\
\hline & $\begin{array}{l}\text { Barra } \\
\text { lateral }\end{array}$ & $\begin{array}{l}\text { Similar ao banner, mas com disposição vertical e normalmente de } \\
\text { maior tamanho ( } 600 \text { a } 120 \text { pixeis). Tem ainda a vantagem de não } \\
\text { desaparecer com a navegação vertical do utilizador. }\end{array}$ \\
\hline CLASSIFICADOS & & $\begin{array}{l}\text { Pequenos enunciados similares aos que se podem encontrar nos } \\
\text { jornais "tradicionais", listados por categorias de produtos ou tipo } \\
\text { de mensagem (venda, compra...). }\end{array}$ \\
\hline
\end{tabular}

Fonte: Sebastião (2011, p. 17-18).

Embora a atenção maior do público em geral para a publicidade online esteja voltada para os anúncios de exibição, especialmente aos banners, segundo dados da pesquisa Digital AdSpending, realizada pelo comScore e divulgada pelo IAB Brasil (2016, doc. Eletrônico), a maior parte das verbas publicitárias vêm do segmento de search com a quantia de R \$ 5,169 bilhões; em segundo lugar aparecem os anúncios por display e redes sociais com $\mathrm{R} \$ 3,148$ bilhões; e em terceiro aparecem os anúncios de vídeo, que somam $\mathrm{R} \$$ 1,038 bilhão. E esses números devem continuar crescendo, segundo o presidente do IAB Brasil, Andre Izay.

Os formatos de publicidade possuem nomenclaturas variadas que não contribuem para a criação de uma identidade ou de uma linguagem comum. Os formatos também são diversos dependendo de qual viés se está observando. Enquanto Sebastião observa os 
formatos apresentados pelo utilizador, a DoubleClick - empresa de tecnologia de serviços em publicidade do Google - leva em consideração os anúncios de exibição, nomeados pela autora e reclassifica os anúncios digitais, no caso, os banners, em termos de interatividade.

As formas estratégias para gerar visibilidade aos anunciantes são várias, e sairá na frente quem souber aproveitar mais os recursos publicitários disponíveis na web. Um aspecto que está em foco, atualmente, é a interatividade dos anúncios, que podem ser utilizados de forma simples, mas também de forma interessante e surpreendente. E como "[...] na web, o vínculo também é estabelecido por meio da interatividade [...]". (FERNANDES, 2011, p. 62), a mesma é um dos aspectos de grande importância a ser considerado na criação das peças publicitárias nesta ambiência.

As ferramentas vão se aperfeiçoando e neste contexto surgiram os widgets, que por ser uma forma de Rich Media mais avançada acabou recebendo um nome próprio e chegou oferecendo possibilidades de vincular o internauta, seja pela dramatização ou mesmo pela interação (FERNANDES, 2011). Duarte (2011, p. 73) explica que a forma:

Rich media advanced contempla todos os recursos de mídia enriquecidos com o uso avançado de atributos que abrangem maior interação, tal como a possibilidade de inserir até mesmo vídeos de alta qualidade nas peças, games, formulários completos, transmissão ao vivo, diversos menus, cadastros de compartilhamento com outros usuários sem precisar clicar e sair da página em que a peça está veiculada. São peças avançadas que potencializam a exploração da marca/produto por meio de maior interatividade e engajamento com o usuário.

Duarte relata que "[...] tais anúncios possuem maiores impacto e eficácia, além de permitir grande variedade criativa." (DUARTE, 2011, p. 74). E o impacto desejado pelos anunciantes nem sempre busca o clique, já que neste tipo de peça apenas com a interação já é possível que o usuário consiga todas as informações necessárias para conhecer o produto ou serviço que está sendo oferecido.

Enquanto os anúncios de texto se vendem com palavras e os anúncios de exibição vendem com foto, os rich media oferecem outras maneiras para envolver sua audiência. Os anúncios podem expandir-se, flutuar, descascar... e suscitar respostas ao público-alvo. É possível ainda mensurar a taxa de interação ${ }^{8}$ para saber se a campanha em questão está tendo sucesso ou não (DOUBLECLICK CREATIVE..., 2016). 0 formato mencionado serve, então, para os objetivos mais simples, como gerar cliques, até os mais ambiciosos, como

\footnotetext{
80 índice Digital de Interatividade (IDI) é fruto da relação do volume total de impressões de um anúncio e o volume de interações com essa peça (DUARTE, 2011).
} 
criar conscientização de uma marca, envolver o público na experiência de publicidade e rastrear o comportamento do usuário com o uso de métricas.

A interatividade é uma característica que surgiu com os avanços da tecnologia já que os mesmos permitiram que a comunicação se tornasse multidirecional e oferecendo uma participação ampla ao utilizador do sistema. McMillan (2002) considera que a interatividade não é uma propriedade exclusiva da tecnologia, mas também está vinculada a quem utiliza tal tecnologia. É importante considerar a experiência do usuário, suas percepções ao conceber novos meios e novos processos interativos.

McMillan (2002) determinou três tipos fundamentais e diferentes de interatividade:

a) utilizador para utilizador, ou seja, quando os usuários interagem uns com os outros (comunicação interpessoal);

b) utilizador para documentos - quando o usuário interpreta e usa as mensagens disponibilizadas (mass media);

c) e utilizador para sistema - quando há um diálogo entre o usuário e seu computador. Esse tipo corresponde à tradição da pesquisa sobre a interface entre o homem e a máquina.

O primeiro tipo (utilizador para utilizador) está centrado nas mudanças que as novas tecnologias provocaram nas comunicações humanas, mas o importante aqui é atentar para o comportamento dos comunicadores considerando os meios de comunicação apenas como ferramentas proporcionadas para o controle do processo.

Já no segundo tipo (utilizador-documento) devemos considerar o papel das audiências e o quanto essas são ativas. Matos (2005) informa que importa aqui o modo como os indivíduos interpretam e utilizam mensagens viabilizadas via meios de comunicação de massa e a partir daí criam novos conteúdos. Com isso os receptores passam a ser elementos ativos do processo de comunicação, transformando-se em emissores, com controle sobre os conteúdos.

E o terceiro tipo de interação (utilizador-sistema) evidencia a interface. Aqui o foco está em como os humanos comunicam-se com os computadores, considerando aspectos tanto de design quanto de percepção humana. Aqui a comunicação ocorre através da interface apresentada pelo sistema.

Durante vários anos, a tecnologia Flash foi a alternativa mais viável para quem quisesse utilizar animações nas páginas Web. Isso funcionava, pois ele estava presente em quase todos os navegadores e proporcionava que o formato fosse utilizado sem maiores 
problemas. Acontece que devido às inconsistências dos navegadores, muitos atributos eram duplicados, além de o Flash causar muita instabilidade e, eventualmente, fechar o navegador. Isso fez com que outras opções surgissem e o HTML59 ${ }^{9}$ foi criado para oferecer conteúdo multimídia de forma confiável, sem ter que criar opções para os diferentes navegadores (VIEIRA, 2014).

0 HTML5 pode ser utilizado em conjunto com a linguagem de programação JavaScript e possibilita vários tipos de interação, com novos elementos, atributos e comportamentos. Esta tecnologia traz inovações que suprem o que antes era feito apenas com o Flash já que consegue incorporar elementos e linguagens gráficas capazes de atrair a atenção de usuários tanto de dispositivos móveis quanto computadores. Para o usuário final, pouca coisa muda, apenas a página parece ficar mais rápida. No entanto, as animações podem ter muito mais detalhes, e por estarem integradas ao código das páginas web consomem muito menos recursos do sistema para serem produzidas (CANALTECH, 2016).

Então, a publicidade digital usa recursos para ampliar a interatividade de seus anúncios e o caminho natural foi a utilização de banners mais simples, passando pelo uso intenso da tecnologia flash, e agora, com seu encerramento, o caminho mais lógico é o uso de HTML5 para a construção de peças rich media cada vez com mais impacto.

Existem vários tipos de anúncios Rich Media, desde os mais simples até os mais avançados, e a DoubleClick (2016) classifica-os em:

a) In-page - é o formato de anúncio mais básico, aparece dentro das fronteiras definidas em uma página e não expande e nem cobre outros conteúdos;

b) Expanding - começa como um anúncio padrão em uma página da Web e, em seguida, se expande sobre o conteúdo da página automaticamente ou quando um usuário interage com ele;

c) Floating - também conhecido como intersticial, flutua no topo da página e a ele não é atribuído um espaço de anúncio fixo;

d) In-Page with Floating - Utiliza os anúncios In-page e Floating ao mesmo tempo;

e) também existem os tipos tandem, push-down, peel-down, Youtube Masthead, lightbox, in-stream e interactive in-stream, porém menos utilizados.

\footnotetext{
9 A nova versão da linguagem de marcação HTML agrega novos recursos que permitem uma maior estruturação dos documentos, mais funcionalidades, independência de plataforma, tratamento de exceção e suporte nativo aos recentes conteúdos multimídias. Também consegue excluir incômodos que temos ao utilizar bibliotecas e plugins externos que nem sempre funcionam como deveriam nos navegadores distintos (BOTELHO, 2016).
} 
A constante evolução dos dispositivos coloca em cena novos desafios para a publicidade, e, com isso, os profissionais precisam estar sempre pensando rápido para concretizar estratégias de comunicação que tenham eficiência e dominem esses ambientes. O cenário atual nos faz pensar na comunicação com o público, em várias mídias e não de maneira isolada já que o consumidor consome conteúdo (e publicidade) por vários meios independentemente de hora e lugar, e, muitas vezes, em mais de um canal simultaneamente.

\section{Proposta de matriz}

A proposta da matriz foi pensada para que fosse possível fazer um desenho, que represente como a publicidade está construindo o seu espaço na plataforma digital e neste sentido, a cartografia surgiu como opção metodológica que permite acompanhar os movimentos de transformação da paisagem ${ }^{10}$ (ROLNIK, 1989). "A cartografia é um método com dupla função: detectar a paisagem, seus acidentes, suas mutações e, ao mesmo tempo, criar vias de passagem através deles." (ROLNIK, 1989, p. 6).

A cartografia é um procedimento/metodologia/método que tem sido usado nas últimas décadas nas ciências sociais e humanas, tendo se destacado, no Brasil, na área da psicanálise e da educação. Começou a adentrar à comunicação há poucos anos, sendo foco de interesse de pesquisadores que buscam novos caminhos, não pela novidade, mas pela possibilidade de construir uma percepção diferenciada sobre os objetos do campo (ROSÁRIO, 2013, p. 85).

Vale lembrar que a cartografia foi ativada por Deleuze e Guattari11 como um dos princípios do rizoma, mas vem se atualizando como um método e/ou procedimento de pesquisa no Brasil. A cartografia "[...] visa acompanhar um processo, e não representar um objeto [...]." (KASTRUP, 2009, p. 32). Rolnik e Kastrup defendem que a cartografia é um método, mas explicam que ela não segue o ponto de vista tradicional do método, que se propõe a seguir um percurso previamente determinado por regras ou protocolos na procura de uma verdade absoluta, mas busca traçar um percurso enquanto o percorre.

Sobre este aspecto Baccin afirma que "[...] o que caracteriza e dá contornos à pesquisa vai ser o tipo de sensibilidade, que o cartógrafo se permitirá fazer prevalecer, na medida em que seu trabalho exigir." (BACCIN, 2013, p. 10). Outro aspecto importante desta pesquisa é ressaltado por Bonin, quando a pesquisadora afirma que "[...] a dimensão

\footnotetext{
10 Embora seja muito utilizada pelas engenharias e pela geografia, a cartografia já vem sendo utilizada pelas ciências sociais como método ou metodologia de investigação.

11 O conceito de cartografia de Deleuze e Guattari aparece na obra Mil Platôs (1995) como o quinto princípio do rizoma.
} 
histórica, em qualquer âmbito que busquemos investigar, é fundamental para entender a ação configuradora das mídias que buscamos tornar inteligíveis." (BONIN, 2013, p. 58). E ela acrescenta:

\begin{abstract}
Nós, pesquisadores do campo da comunicação, estamos sendo desafiados a pensar/trabalhar/produzir conhecimentos que possam ajudar a compreender o fenômeno da midiatização - um processo histórico - no que se refere às transformações socioculturais provocadas pelo mesmo; ao caráter conformador da técnica, ao ecossistema midiático nos desenhos das interações, aos funcionamentos institucionais, aos campos, das configurações espaciais e temporais das sociedades, à experiência, à produção de sentido, aos vínculos que aí se produzem, entre outras dimensões (BONIN, 2013, p. 56).
\end{abstract}

A cartografia funciona como uma nova forma de pensar a comunicação, deixa de lado alguns paradigmas pré-estabelecidos e algumas vezes tende a ser considerada um procedimento sem rigor, no entanto, ela é muito mais que isto. 0 pesquisador tem que observar e entrar no objeto, entendendo que são vários caminhos que ele tem a escolher, mas que a escolha por um ou mais pontos vai depender apenas do próprio cartógrafo.

Rolnik (1989) aponta elementos que podem ser considerados para nortear a investigação quando o cartógrafo tiver que sair a campo: critério, princípio, regra, roteiro.

Quadro 5 - Elementos norteadores da investigação cartográfica

\begin{tabular}{|l|l|}
\hline Critério & $\begin{array}{l}\text { O critério é responsável por organizar as escolhas, as direções, porém, precisa estar } \\
\text { sempre aberto à recomposição; é necessário para iniciar e dar um traçado ao percurso, } \\
\text { bem como para encontrar tensionamentos, multiplicidades e focos, decidindo por onde } \\
\text { seguir. Pode servir de auxilio compartilhá-lo desde o início, tornando-o explícito e } \\
\text { relatando suas linhas de fuga. }\end{array}$ \\
\hline Princípio & $\begin{array}{l}\text { É extramoral: visa sobretudo a expansão da vida, é seu parâmetro básico e exclusivo, e } \\
\text { nunca uma cartografia qualquer, tomada como mapa. Esse elemento define do que se } \\
\text { deve ou se pode estar imbuído para dar início e conduzir a pesquisa, bem como ordena } \\
\text { as noções que regem os procedimentos do cartógrafo. Ao que tudo indica, o que } \\
\text { fundamenta o princípio do cartógrafo deve estar ligado a uma razão vitalizante. }\end{array}$ \\
\hline Regra & $\begin{array}{l}\text { Não é configurada por um viés de medidas, padrões e modelos, mas nasce da } \\
\text { sensibilidade do corpo vibrátil do cartógrafo. Trata-se, aqui, de avaliar o quanto se } \\
\text { suporta, em cada situação [...] A regra do cartógrafo então é muito simples: é só nunca } \\
\text { esquecer de considerar esse "limiar". A regra constrói-se, então, na conexão com o } \\
\text { objeto, o pesquisador, o princípio, a proposta da investigação. É possível que ela seja } \\
\text { atravessada pela subjetividade e pela intuição que vão ao encontro das singularidades } \\
\text { do objeto, mas oferecem variações que abrigam também a objetividade e a } \\
\text { sistematização, tendo em vista o modo como o caminho se apresenta. A regra ajuda } \\
\text { ainda a traçar estratégias e orienta sobre como conduzir o processo. }\end{array}$ \\
\hline Roteiro & $\begin{array}{l}\text { Cada cartógrafo vai definindo e redefinindo para si, constantemente. O roteiro - assim } \\
\text { como o objeto, a problematização e o pesquisador - vai sendo construído e } \\
\text { desconstruído, territorializado e desterritorializado durante toda a trajetória, já que os } \\
\text { elementos da pesquisa interpenetram-se de forma dinâmica. }\end{array}$ \\
\hline
\end{tabular}

Fonte: Adaptado de Rolnik (1989). 
Resumindo, os critérios dizem respeito à decisão de por onde seguir; os princípios são os parâmetros básicos e exclusivos desta investigação; e as regras referem-se à reavaliação constante dos passos dados na pesquisa, a correção da rota, quando necessária, e a adequação das estratégias ao processo de investigação. Estes passos serão importantes para na sequência escrever o roteiro da pesquisa, que vai se concretizar no desenho dos mapas possíveis.

É inegável que o pesquisador assume papel importante na teorização e na aplicação do procedimento cartográfico e na construção deste caminho potencialidades, para a ciência e para a produção da realidade com a construção de seus mapas.

Se a pesquisa desenvolvida a partir da matriz optar por fazer uma análise histórica, sugerimos que o acesso aos portais anteriores utilize a ferramenta disponível na web denominada Internet Wayback Machine (IWM), que constitui um banco de dados digital12, que funciona como um museu digital, já que arquiva páginas da web desde 1996. Este site permite visualizar como o design e a usabilidade dos sites evoluiu ao longo do tempo e é possível conferir tendências que marcaram épocas, especialmente na publicidade digital.

Quanto ao percurso metodológico, foi necessário criar categorias para sistematizar as fases da WebPP e os modos de desenvolvimento. São elas: (1) transposição dos meios tradicionais; (2) tentativa de criar para o meio digital; (3) interação com os usuários; (4) transposição da web para mobile. Na sequência, trabalhamos com o roteiro, ou seja, um esboço dos passos da pesquisa, que foi construído e desconstruído ao longo da caminhada. 0 roteiro inicial previa a coleta dos dados que aconteceu ao longo da pesquisa, e na medida em que novos insights surgiram e novas opções foram levadas à reflexão.

Vários caminhos de análise surgiram e a utilização da cartografia é justificada pela complexidade dos movimentos que se estabelecem nos processos comunicacionais. Para a construção da matriz, utilizamos os elementos norteadores sugeridos por Rolnik.

\subsection{Critério}

Nossa análise observou a organização dos Portais institucionais em quatro momentos principais:

a) transposição dos meios tradicionais;

b) tentativa de criar para o meio digital;

\footnotetext{
12 A ferramenta mapeia o número de vezes que os sites foram rastreados pela Wayback Machine, não quantas vezes o local foi
} realmente atualizado. 
c) interação com os usuários;

d) e transposição da web para mobile.

\subsection{Roteiro}

Em cada momento determinado como critério, foi observada:

a) a forma genérica como os conteúdos são apresentados (número de colunas, disposição dos espaços); por exemplo, a distribuição das colunas dos portais e os espaços de publicidade utilizados.

b) a partir dos prints possíveis dos sites institucionais qual o tipo de publicidade (PINHO, 2001);

c) ainda nos anúncios, a prática publicitária (PINHO, 2001) em foco no momento;

d) tipos de interatividade propostos por McMillan (2002):

- utilizador para utilizador,

- utilizador para documentos,

- utilizador para sistema;

e) formatos dos anúncios publicitários conforme apresentados ao utilizador, seguindo a classificação de Sebastião (2011) que inclui três principais formatos de publicidade online - (1) os anúncios de pesquisa, (2) os anúncios de exibição (display ads), e (3) os classificados;

f) tecnologia predominante que foi utilizada, na qual observamos a presença dos elementos imagens estáticas (JPG), GIF’s, Flash Player (animações), JavaScript e HTML5, ou seja, o novo padrão para a estruturação e apresentação de conteúdo na internet 13 ;

g) evolução de anúncios digitais em termos de interatividade - Banner ou AdServers; Rich Media; Widget ou Rich Media Advanced. Indicados por Fernandes (2011) e Duarte (2011, p. 73).

\subsection{Princípio}

Todos os elementos do roteiro devem ser encontrados em cada um dos critérios observados. As alterações nas práticas é que vão delimitar o que faz parte de cada fase.

\footnotetext{
13 O HTLM5 trouxe melhorias e novas funcionalidades de semântica e acessibilidade, além de melhorar o suporte aos mais recentes conteúdos multimídias. Suas principais mudanças são: melhor tratamento de exceção, mais tags para substituir scripts, independência de plataforma e redução da necessidade de plugins externos.
} 


\subsection{Regra}

Observamos as fronteiras que se mostram no campo e nas relações com os sujeitos e objetos. Rosário (2013, p. 88) lembra que é possível que a regra:

[...] seja atravessada pela subjetividade e pela intuição que vão ao encontro das singularidades do objeto, mas oferecem variações que abrigam também a objetividade e a sistematização, tendo em vista o modo como o caminho se apresenta.

Quadro 6 - Matriz de análise para a publicidade na ambiência digital

\begin{tabular}{|c|c|c|c|}
\hline \multicolumn{4}{|c|}{ Marca } \\
\hline \multicolumn{4}{|c|}{ Período } \\
\hline \multirow{3}{*}{$\begin{array}{l}\text { Cenário } \\
\text { Web }\end{array}$} & \multicolumn{3}{|c|}{ Web 1.0 - consumo de informações (unidirecional) } \\
\hline & \multicolumn{3}{|c|}{ Web 2.0 - participação (Mídias sociais) (bidirecional) } \\
\hline & \multicolumn{3}{|c|}{ Web 3.0 - aperfeiçoamento da tecnologia (comunicação colaborativa) } \\
\hline \multirow{4}{*}{\multicolumn{2}{|c|}{$\begin{array}{l}\text { Critérios pré- } \\
\text { definidos }\end{array}$}} & \multicolumn{2}{|c|}{ Transposição dos meios tradicionais } \\
\hline & & \multicolumn{2}{|c|}{ Tentativa de criar para o meio digital } \\
\hline & & \multicolumn{2}{|l|}{ Interação com os usuários } \\
\hline & & \multicolumn{2}{|c|}{ Transição da web para mobile } \\
\hline \multirow{5}{*}{\multicolumn{2}{|c|}{ Tipo de publicidade 14}} & Publicidade de produto & Publicidade comparativa \\
\hline & & Publicidade de serviços & Publicidade cooperativa \\
\hline & & $\begin{array}{c}\text { Publicidade genérica (ou } \\
\text { de commodities) }\end{array}$ & Publicidade de promoção \\
\hline & & Publicidade de varejo & Publicidade legal \\
\hline & & $\begin{array}{l}\text { Publicidade de } \\
\text { classificados }\end{array}$ & Não se aplica \\
\hline \multirow{5}{*}{\multicolumn{2}{|c|}{ Tarefa da publicidade }} & \multicolumn{2}{|c|}{ Divulgação da marca (de produto ou serviço) ou empresa } \\
\hline & & \multicolumn{2}{|c|}{ Promoção da marca ou empresa para seus consumidores } \\
\hline & & \multicolumn{2}{|c|}{ Criação de mercado para a marca ou empresa } \\
\hline & & \multicolumn{2}{|l|}{ Expansão do mercado } \\
\hline & & \multicolumn{2}{|l|}{ Correção do mercado } \\
\hline
\end{tabular}

${ }^{14}$ Os tipos e as tarefas da publicidade estão baseados em Pinho (2001). 


\begin{tabular}{|c|c|}
\hline & Educação do mercado \\
\hline & Consolidação do mercado \\
\hline & Manutenção do mercado \\
\hline \multirow{4}{*}{ Formatos $^{15}$} & Anúncios de pesquisa \\
\hline & Anúncios de exibição $\rightarrow$ banner \\
\hline & Classificados \\
\hline & Não se aplica \\
\hline \multirow{5}{*}{$\begin{array}{l}\text { Tecnologia } \\
\text { predominante que foi } \\
\text { utilizada }\end{array}$} & Imagem estática \\
\hline & Gif \\
\hline & Flash \\
\hline & JavaScript \\
\hline & HTML5 \\
\hline \multirow{3}{*}{$\begin{array}{l}\text { Tipos de } \\
\text { interatividade }^{16}\end{array}$} & Utilizador para utilizador \\
\hline & Utilizador para documentos \\
\hline & Utilizador para sistema \\
\hline \multirow{4}{*}{$\begin{array}{l}\text { Interatividade em } \\
\text { anúncios }^{17}\end{array}$} & Banner ou AdServers; \\
\hline & Rich Media; \\
\hline & Widget ou Rich Media Advanced \\
\hline & Não se aplica \\
\hline
\end{tabular}

Fonte: Elaborada pela autora.

Após demonstrar e argumentar o processo de elaboração da matriz de análise, o próximo passo é a aplicação da matriz ao corpus selecionado para cada pesquisa.

Na pesquisa original, todo novo layout viável (que completava seu carregamento, pelo menos na maior parte) de cada marca foi selecionado com o auxílio da ferramenta Way Back Machine e a partir daí as homepages foram descritas considerando os elementos aqui expostos.

\footnotetext{
${ }^{15}$ Os formatos foram construídos com base em Sebastião (2011).

16 Os tipos de interatividade seguem a classificação indicada por McMillan (2002).

${ }^{17}$ A interatividade em anúncios está construída com base em Fernandes (2011) e Duarte (2011).
} 


\section{Considerações finais}

No ecossistema midiático digital, ocorrem transformações estruturais na publicidade e em suas práticas e é possível perceber que a publicidade tradicional está migrando para a internet, pois conforme aumenta o uso da rede pelos consumidores, desloca-se também o investimento das empresas para esse meio, já que o custo da publicidade na ambiência digital é menor, e a flexibilidade é maior em relação aos outros meios de comunicação. As práticas publicitárias mudam em função de transformações envolvendo o contexto, os anunciantes e o público de forma geral.

A matriz servirá para a observação das mudanças e dos formatos dos anúncios publicitários em sites institucionais de marcas no cenário da nova ecologia midiática, e um dos aspectos que com certeza evidenciará é o espaço dedicado aos anúncios, que aumentou de forma considerável ao longo dos anos, fato que revela uma adesão maior dos anunciantes à publicidade veiculada na web.

A evolução das formas de comunicação entre empresas e consumidores faz parte de um processo que tem relação direta com a tecnologia, que insere possibilidades de transmissão de mensagens cada vez mais complexas e eficazes. É necessário que os responsáveis pela comunicação considerem sempre as ferramentas disponíveis no mercado, já que as possibilidades existentes possibilitam direcionar as mensagens de acordo com o público, e, quanto mais específica e avançada a tecnologia, mais provável a chance de alcançar os objetivos propostos e trazer retorno para os anunciantes.

Existem muitas oportunidades, nesse sentido, os profissionais de comunicação precisam sair das práticas e dos formatos já conhecidos a fim de abrirem espaço a outros cenários. Porém, não devemos esquecer que o essencial da prática publicitária não se modificou, isto é, seu objetivo subjacente referente à venda ou à promoção. Mudaram, sim, as ferramentas tecnológicas para que os objetivos sejam alcançados e, com isso, as maneiras de se interagir com os usuários.

Outra questão que deve ser considerada é que o avanço da tecnologia acostuma os usuários a esperarem cada vez menos, a ansiarem pela resposta imediata, e esse tipo de situação é que movimenta a busca por peças que não demorem para carregar, que não precisem de esforços (plug-ins) extras para se completarem e que sejam acessíveis em qualquer dispositivo. Além disso, há que se considerar que, especialmente quando acessadas via mobile, as páginas utilizam o pacote de dados do usuário. Dessa forma, não é 
recomendado o alto consumo de dados por acesso à página, o que ocasionaria inclusive maiores custos para o consumidor.

Em suma, a publicidade é inconstante e vai seguir mudando. Isso acontece porque as pessoas que a fazem e a quem ela se destina (público-alvo) estão em constante mudança. Aos publicitários, cabe adaptarem-se e entenderem que hoje, mais do que antes, medição e monitoramento das atividades desenvolvidas é essencial, tanto quanto a capacidade criativa de surpreender e impactar os usuários desse ecossistema.

\section{Referências}

ADLER, Richard; FIRESTONE, Charles. A conquista da atenção. A publicidade e as novas formas de comunicação. São Paulo: Nobel, 2002.

BACCIN, Alciane Nolibos. Cartografia - o desafio metodológico de construir conhecimento na pesquisa em jornalismo. In: SEMINÁRIO DE PESQUISA EM COMUNICAÇÃO, 5., 2013, Santa Maria. Anais... Santa Maria, 2013. 15p.

BARICHELLO, Eugênia Maria Marino da Rocha. Midiatização e cultura nas organizações da contemporaneidade: o processo de midiatização como matriz de práticas sociais. In: MARCHIORI, Marlene (Org.). Contexto organizacional midiatizado. São Caetano do Sul: Difusão Editora; Rio de Janeiro: SENAC RJ, 2014.

BONIN, Jiani Adriana. A dimensão metodológica na pesquisa comunicacional e os desafios da observação em perspectiva histórica. In: MALDONADO, Alberto Efendy; BONIN, Jiani Adriana; ROSÁRIO, Nísia Martins do (Org.). Perspectivas metodológicas em

Comunicação: novos desafios na prática investigativa. Barcelona: Salamanca, 2013. p. 5473.

BOTELHO, Raimundo. As novidades do HTML5. Devmedia, Rio de Janeiro, [2016]. Disponível em: <http://www.devmedia.com.br/as-novidades-do-html5/23992>. Acesso em 19 set. 2016.

DOUBLECLICK. 2016. Disponível em: <https://www.doubleclickbygoogle.com/pt-br/> Acesso em: 15 fev. 2016

DOUBLECLICK CREATIVE Solutions Help. HOW rich media works - What is rich media? Doubleclick, [S.l.], [2016]. Disponível em:

<https://support.google.com/richmedia/answer/2417545?hl=en>. Acesso em: 17 fev. 2016

DUARTE, Marília. Métricas de mídia online. In: GOMES, Wilson; REIS, Lucas (Org.).

Publicidade digital: formatos e tendências da nova fronteira publicitária. Salvador: P\&A, 2011. p. 65-84. 
FERNANDES, Breno. Do banner ao widget, passando pelo rich media: dimensão e interatividade como principais aspectos para anúncios na web. In: GOMES, Wilson; REIS, Lucas (Org.). Publicidade digital: formatos e tendências da nova fronteira publicitária. Salvador: P\&A, 2011. p. 47- 63.

FOLHA DE S. PAULO. Publicidade e patrocínio giram R 116 bilhões. Folha de S. Paulo, São Paulo, 22 out. 2013. Mercado. Disponível em:

<http://www1.folha.uol.com.br/fsp/mercado/135118-publicidade-e-patrocinio-giram-r116-bilhoes.shtml>. Acesso em: 2 jan. 2014.

GABRIEL, Martha. Marketing na era digital: conceitos, plataformas e estratégias. São Paulo: Novatec, 2010.

GENARO, Thiago de Mello. Práticas publicitárias: linguagem, circuito e memória na produção de anúncios impressos no Brasil (1951-1965). Dissertação (Mestrado em História Social) - Faculdade de Filosofia, Letras e Ciências Humanas, Universidade de São Paulo, São Paulo, 2012. Disponível em: <http://www.teses.usp.br/teses/disponiveis/8/8138/tde22042013-104447/pt-br.php>. Acesso em: 10 abr. 2013.

GHISLENI, Taís Steffenello. Portais institucionais na web: análise de anúncios publicitários. Tese (Doutorado em Comunicação) - Programa de Pós Graduação em Comunicação, Universidade Federal de Santa Maria, Santa Maria, 2016. Disponível em: $<$ https://pt.scribd.com/document/353758224/PORTAIS-INSTITUCIONAIS-NA-WEBANALISE-DE-ANUNCIOS-PUBLICITARIOS-NO-ECOSSISTEMA-MIDIATICO >. Acesso em: 14 jul. 2017.

IAB BRASIL. Número de investimento 2016. São Paulo, 2016. Disponível em: <http://iabbrasil.net/assets/upload/boas_praticas/1457447232.pdf?>. Acesso em: 9 mar. 2016.

JENKINS, Henry. Cultura da convergência. São Paulo: Aleph, 2009.

KASTRUP, Virginia. 0 funcionamento da atenção no trabalho do cartógrafo. Psicologia e Sociedade, Porto Alegre, v. 19, n. 1, p. 15-22, 2007. Disponível em: <http://dx.doi.org/10.1590/S0102-71822007000100003>. Acesso em: 24 nov. 2013.

MATOS, Valter de. Usabilidade na web e usabilidade na televisão interactiva. Porto: Faculdade do Porto, 2005. Dissertação (Mestrado em Tecnologia Multimédia) - Faculdade de Engenharia da Faculdade do Porto, Porto, 2005.

McLUHAN. Marshall. Os meios de comunicação como extensões do homem. São Paulo: Cultrix, 1964.

McLUHAN, Marshall. Os meios de comunicação como extensões do homem. 14. ed. São Paulo: Cultrix, 2007. 
McMILLAN, Sally J., Exploring models of interactivity from multiple research traditions: users, documents and systems". In LIEVROUW, Leah A.; LIVINGSTONE, Sonia (Org.).

Handbook of new media. London: Sage, 2002. Disponível em:

<http://sk.sagepub.com/reference/hdbk_newmedia/n12.xml>. Acesso em: 29 jun. 2016.

MEYROWITZ. Joshua. Oltre il senso del luogo: L'impatto dei media elettronici sul comportamento sociale. [S.I.]: Baskerville, 1984.

PINHO, José Benedito. Comunicação em marketing: princípios da comunicação mercadológica. Campinas: Papirus, 2001.

PINHO, José Benedito. Publicidade e vendas na Internet: técnicas e estratégias. São Paulo: Summus, 2000.

REDAÇÃO ADNEWS. Infográfico: 21 anos de internet comercial no Brasil. Adnews, São Paulo, 1 jun. 2016. Disponível em: <http://adnews.com.br/internet/infografico-21-anos-deinternet-comercial-no-brasil.html>. Acesso em: 1 jun. 2016.

ROLNIK, Suely. Cartografia ou como pensar com o corpo vibrátil. São Paulo: Estação Liberdade, 1989. Disponível em:

<http://www.pucsp.br/nucleodesubjetividade/Textos/SUELY/pensarvibratil.pdf>. Acesso em: 24 de nov. 2013.

ROSÁRIO, Nisia Martins do. Mitos e cartografias: novos olhares metodológicos na comunicação. In: MALDONADO, Alberto Efendy; BONIN, Jiani Adriana; ROSÁRIO, Nísia Martins do (Org.). Perspectivas metodológicas em Comunicação: novos desafios na prática investigativa. Barcelona: Salamanca, 2013. p. 74-101.

SEBASTIÃO, Sónia. Formatos da publicidade digital: sistematização e desambiguação. Revista Comunicação e Sociedade, Braga, v. 19, p. 13-24, 2011. Disponível em: <http://www.lasics.uminho.pt/ojs/index.php/comsoc/article/view/894>. Acesso em: 4 maio 2014.

SCOLARI, Carlos A. Ecología mediática, evolución e interfaces. Hipermediaciones, [S.I.], 2012. Disponível em: <http://hipermediaciones.com/2012/04/23/ecologia-mediaticaevolucion-e-interfaces/>. Acesso em: 11 out. 2012.

SCOLARI, Carlos A. Media ecology: explorando la metáfora. Hipermediaciones, [S.l.], 2010. Disponível em: <https://hipermediaciones.com/2010/06/24/media-ecology-explorandola-metafora/>. Acesso em: 1 jun. 2012.

SCOLARI, Carlos A. Media ecology. Map of a theoretical niche. Quaderns del CAC 34, Barcelona, v. 13, n. 1, p. 17-25, jun. 2010. Disponível em:

<http://www.cac.cat/pfw_files/cma/recerca/quaderns_cac/Q34_Scolari_EN.pdf>. Acesso em: 4 jan. 2016. 
STRATE, Lance. A queda das nações: o destino dos sistemas sociais no novo ambiente midiático. E-compós, Brasília, v. 14, n. 3, set./dez. 2011. Disponível em:

<http://www.compos.org.br/seer/index.php/e-compos/article/view/709/548>. Acesso em: 10 out. 2016.

STRAUSS, Judy; FROST, Raymond. E-marketing. 6. ed. São Paulo: Pearson Prentice Hall, 2011.

STRUTZEL, Tércio. Presença digital: estratégias eficazes para posicionar sua marca pessoal ou corporativa na web. Rio de Janeiro: Alta Books, 2015.

SERÁ o fim do Flash? Vegaweb, São Paulo, 2015. Disponível em:

<http://www.vegaweb.com.br/blog/2015/09/sera-o-fim-do-adobe-flash/>. Acesso em: 12 jul. 2016.

VIEIRA, Nando. Usando a tag vídeo no HTML5. Nando Vieira, [S.l.], 2014. Disponível em: <https://nandovieira.com.br/usando-a-tag-video-no-html5>. Acesso em: 19 set. 2016.

ZEFF, Robbin; ARONSON, Brad. Publicidade na Internet. 2. ed. Rio de Janeiro: Campus, 2000 .

\title{
Proposed matrix for the analysis of web advertising
}

\begin{abstract}
This article presents a methodological matrix for analysis of advertisements on websites, and its construction is based on the theses of Marshall McLuhan and Neil Postman, under the ecological aspect, and also on the proposals of Pinho, Sebastião, McMillan, Fernandes and Duarte. The matrix was constructed using the cartography as a methodological strategy, since it allows to follow the movements of transformation of the landscape, and its results show that the possibilities offered by technology are responsible for changes in advertising practices considering that with each new aspect inserted, new experiences were provided and advertising was building its space on the web.
\end{abstract}

\section{Keywords}

Communicative strategies. Advertising on the web. Media ecology. Cartography in Communication. Commercials.

Recebido em 29/03/2017

Aceito em 21/06/2017 